ISSN 0143-4543

\title{
Poor and Sick: Estimating the relationship between Household Income and Health
}

\author{
By \\ Athina Economou*, and Ioannis Theodossiou**
}

Discussion Paper 2010-04

February 2010

\section{Editor: Dr W David McCausland www.abdn.ac.uk/business/}

\footnotetext{
The financial support of the European Commission under the Fifth Framework Programme "Quality of Life and Management of Living Resources" (contract number: QLRT-2001-02292) is gratefully acknowledged. The authors are grateful to two anonimus referees of this Journal for very helpful comments.

* Lecturer, Department of Economics, University of Thessaly, Greece.

*** Coresponding Author. Centre for European Labour Market Research, University of Aberdeen Business School, Economics, University of Aberdeen, UK.
} 


\title{
Poor and Sick: Estimating the relationship between Household Income and Health
}

\author{
Athina Economou*, Ioannis Theodossiou ${ }^{* *}$
}

\begin{abstract}
This study evaluates the effect of the individual's household income on their health at the later stages of working life. A structural equation model is utilised in order to derive a composite and continuous index of the latent health status from qualitative health status indicators. The endogenous relationship between health status and household income status is taken into account by using IV estimators. The findings reveal a significant effect of individual household income on health before and after endogeneity is taken into account and after a host of other factors which is known to influence health, including hereditary factors and the individual's locus of control. Importantly, it is also shown that the childhood socioeconomic position of the individual has long lasting effects on health as it appears to play a significant role in determining health during the later stages of working life.
\end{abstract}

JEL Classification Code: C25, C35, I12

Keywords: Latent health, Household income, Socioeconomic status, Endogeneity

The financial support of the European Commission under the Fifth Framework Programme "Quality of Life and Management of Living Resources" (contract number: QLRT-2001-02292) is gratefully acknowledged. The authors are grateful to two anonimus referees of this Journal for very helpful comments.

* Lecturer, Department of Economics, University of Thessaly, Greece.

${ }^{* * *}$ Coresponding Author. Centre for European Labour Market Research, University of Aberdeen Business School, Economics, University of Aberdeen, UK. 


\section{Introduction}

Research shows that decreasing socio-economic status (SES) is associated with an increase in the risks of ill health. Evidence shows that there is a close relationship between social class and general health status and that social class is a summary measure implying differences in income, education, environment and behaviour. It also appears that cognitive functioning and mental health are positively correlated with social class, but physical health exhibits no strong relationship (Mayer and Wagner, 1993). Yet, social class is an important factor in accounting for racial and ethnic differences in health (Smith and Kington, 1997a, 1997b; Navarro, 1990). As Mackenbach et al. (1990) shows variation in mortality rates and health is related more to individuals' socio-economic conditions than to the level of medical provision to the extent that the contribution of medical care is surpassed by the impact of the factors which affect the initial incidence of diseases and infections among the population.

In view of the above there is a rising concern among policy makers that inequalities in health are widening (Smith, 1999; Wilkinson, 1986). The reason is that if poverty affect the health status, then increases in the incidence of poverty should be expected to have detrimental effects on their health thus on their productive capacity. This would also increase the health bill of the poorest individuals which in turn would increase the burden on public health and welfare provision. Furthermore, the increasing inequality in health should be expected to be most visible among workers at the later stages for working life, since aging is associated with decreasing mental, physical, and psychological capabilities (Mayer and Wagner, 1993). Hence, it is important for policy makers to identify the nature of the SES -health relationships in order to guide current and future policy.

However, the effect of SES on health is not readily assessed since reverse causality, the dynamic nature of the relationship and its state dependence are factors which cannot be dealt with in a simple fashion. Furthermore, the multidimensional nature and the largely unobserved of the true health state in the usual surveys present further challenges to the researchers as they are unable to observe an overall index of the individual's latent health status. 
The present study is a further attempt to evaluate the effect of socioeconomics status on health using a sample of European citizens at the later stage of their working life. It attempts to identify the effect of the individual's equivalised household income, on the individual's health. In doing so it utilises a structural equation models to derive a composite measure of latent health from the facets of individual health and also controls for the reverse causality in the household income - health relationship. The main findings support the existence of a strong and positive relationship between household income and health. This remains strong after the endogeneity or reversed causality is taken into account and after controlling for a host of control variables including hereditary traits and the individual's locus of control. In addition, the socioeconomic position of the respondent's household during childhood appears to also exert its own independent effect upon health.

The policy implications of this paper are important: if childhood and current low SES is reflected in low health status at the later stages of the working life, then SES would have a significant and independent effect on the productive capabilities and labour market participation of the older individuals over and above of the effects that are expected to be present due to the frailty attributable to advancing age. In addition, the retirement decisions of this section of the labour force would be also affected. This would have a direct effect on the national finances of public health, health services and social security.

The paper is organised as follows: Section 2 offers a brief literature review to provide a conceptual basis for the study, Section 3 presents dataset and the variables employed in the study and Section 4 presents the methodological framework. Section 5 discusses the results and Section 6 concludes.

\section{A Brief Literature Review}

There has been substantial progress in research into the association between individual socioeconomic status and health although the research base remains inadequate. Higher socioeconomic status (SES), usually approximated by employment status, education level and income, appears to be associated with better 
physical health (Blakely et al., 2002; Buckley et al., 2004; Demakakos et al, 2008; Ecob and Davey Smith, 1999; Grundy and Holt, 2000; Wagstaff et al., 2001), with improved emotional and psychological health (Everson et al., 2002; Theodossiou, 1998), and with reduced risk of mortality (Gardner and Oswald, 2002; Goldman et al., 1995). Individuals of higher socioeconomic status appear to enjoy a higher survival probability in comparison to the remainder (van Rossum et al., 2000) and individuals in the lower steps of the socioeconomic ladder face a higher burden on ill health. A comprehensive survey of this literature appears in Johansen et al. (2006).

Overall, income and wealth are closely associated with occupation and social class. Income has important effects on individuals' health since it determines individuals' standards of living. Wagstaff et al. (2001) finds that income has the greatest explanatory power in explain ill health, accounting for approximately $60 \%$ of inequality in ill health. Blaxter (1990) shows that the income -health relationship appears to be a non-linear one; as income increases health improves initially, but at the high end of the income scale, there is a small negative effect in health. Navarro (1990) further shows that there are great disparities in health both in terms of mortality and morbidity, due to disparities in wealth and income even if the effects of race are netted out. Thus, though there are differences in health status among ethnic groups in the older workers, such effects are driven by disparities in income. Van Doorslaer et al. (1997) find that income inequality is strongly correlated with health inequality across countries. Socioeconomic inequalities in health are found to affect in a differential fashion group of elderly individuals who exhibit different educational, occupational or income characteristics (Martelin, 1994). In contrast, Goldman et al. (1995) documents a strong negative relation between advantageous economic factors and disability status although the effects appear to be lessening for the elderly $\left(\mathrm{O}^{\prime}\right.$ Reilly, 2002). This is also supported by Kiuila and Mieszkowski (2007) who find that the relationship between mortality, income and education becomes weaker with age.

Notwithstanding the above research, the nature of the SES - health relationship is a contested issue among researchers, since the possible reverse causality, the dynamic nature of the relationship and its state dependence are factors which obscure the SEShealth link (Hernández-Quevedo et al., 2008). Indeed, one can argue that not only does income affects health but also health limitations may affect negatively the 
individual's position in the income ladder as they affect his or her earnings capacity. In addition, economic hardship might have a long term effect upon health or accumulated health problems might lead to a belated health status decline. Yet, Hurd and Kapteyn (2001) still finds a significant relationship between wealth and certain types of illnesses after controlling for wealth endogeneity, in line with earlier results of Smith (1999) who shows that the positive income-health relationship holds even after controlling for the endogeneity of income.

To deal with the issue of reverse causality in the SES or income - health relationship a number of empirical methodologies are applied in the literature. Indirect methods use a number of approaches such as limiting the investigation to individuals with an initially good health state (Lynch et al., 1997) or disaggregating the sample to individuals with different levels of health (Fuchs, 2004) or utilising fixed-effect models (Winkelmann and Winkelmann, 1998). Alternatively, a number of studies use the instrumental variables approach (Ettner, 1996; Lindahl, 2005). Furthermore, studies investigate the relationship between socioeconomic status and health in a longitudinal setting (Buckley et al., 2004; Hurd and Kapteyn, 2003; van Ourti, 2004).

Contoyannis et al. (2004) use a dynamic panel models in order to control for the existence of state dependence and heterogeneity in individual health status. They find that positive state dependence affects current health outcomes and that heterogeneity accounts for approximately $30 \%$ of the unexplained variation in health. Yet, the effect of socioeconomic inequalities in health remains important. In line with the above, Hernández-Quevedo et al. (2008) utilise random effects probit models to find that heterogeneity and state dependence are significant factors in explaining current health outcomes.

The literature indicates that individual health status is a multifaceted concept (Duncan et al., 2002). World Health Organisation (WHO, 2003), defines that "health is a state of complete physical, mental and social well-being and not merely the absence of disease or infirmity". Thus, individual health status is comprised by a number of dimensions of individual health, such as physical health and psychological or emotional health state but also facets unobserved to the researcher not possessing direct medical information. However, researchers focus on one or more of the above 
aspects of health state .The vast majority of studies on the SES-health link are based on investigating self reported information on various facets of health status such as functional limitations, psychological status or self evaluation of general health. In view of the multidimensional nature and largely unobserved true health state it is difficult to construct an overall index of the latent health status. Hence, it remains a challenge for researchers to devise health measures that will facilitate a broader index of individual latent health status in the absence of accurate medical information which is not usually available in the common surveys.

The present study is a further attempt to evaluate the effect of socioeconomics status on health using a sample of European citizens at the later stage of their working life. The socioeconomic status is approximated by the level of the individual's current equivalised household income and his or her household level during childhood. The endogenous nature of the socioeconomic position-health relationship is taken into account by the use of the instrumental variable approach. In addition, this study utilises structural equation models to derive a composite measure of latent health from the facets of individual health (Wolfe and van der Gaag, 1981). Thus, it addresses the issue of the multidimensional nature of the latent health status by constructing a continuous composite health indicator with the use of structural equation models.

\section{The Dataset and Variables used}

This study utilises a dataset, derived from a survey administered under the auspices the SOCIOLD (2003-2006) research project funded by the European Commission. The derived dataset is a representative sample of individuals in six European Union countries, namely Denmark, Finland, France, Greece, the Netherlands and the UK ${ }^{1}$. The survey questionnaires are identical for all countries and they are translated by native bilingual researchers. The SOCIOLD (2005) targets exclusively individuals at the later stages of their working life (45 and 65 years). Since, it is a cross-section dataset, the lack of a time series element does not permit the study of the short term dynamics of the SES -individual health relationship. However, it contains a wealth of detailed information on demographic, socioeconomic and health status and it permits

\footnotetext{
${ }^{1}$ Further information on the project can be found at http://www.abdn.ac.uk/sociold/index.hti. The six countries correspond to the nationality of the project partners.
} 
the study of the long term effects of low SES in childhood on the individual health during late adulthood as it provides the relevant information of the individual SES at childhood.

Four measures of individual health state are included in the analysis. They are derived from standardised questions often used in large scale surveys such as the European Community Household Survey and the General Health Questionaire (GHQ). The first is the self-assessed health status (SAHS). It provides information on the overall health condition of the respondent (Groot, 2000; van Doorslaer and Jones, 2003). Studies suggest that there is a systematic variation in self-assessed health responses for different SES, age or gender groups (Crossley and Kennedy, 2002; Grundy and Holt, 2000; Lindeboom and van Doorslaer, 2004). However, Allison and Foster (2004) argue that self-assessed health is a strong predictor of objective health measures, such as mortality. The second is the Mobility Index which is constructed as the sum of scores of respondent's mobility limitations based on responses of the respondents in the following 20 questions regarding the ability of the individual to bathing or dressing, walking one block, walking some blocks (2-3), walking more than a mile, bending, kneeling or stooping, climb one flight of stairs (e.g. a floor, ), climb several flights of stairs, lifting or carrying groceries, do moderate activities (lift or carry weights over $5 \mathrm{~kg}$, moving a table, pull or push large objects like a living room chair, pushing a vacuum cleaner, bowling, or playing golf), do vigorous activities (running, participating in strenuous sports, lifting heavy objects, etc.). The response options are form (0) not at all difficult, (1) a little difficult, (2) very difficult.

The third is the Emotional Health Index1 is constructed by summing up the relevant respondents' scores regarding their recent emotional health and finally the Emotional Health Index 2 is comprised by the sum of scores in questions regarding respondents' recent emotional condition. Details of the definition of the above variables are reported in Table 1 (first panel). 
A number of personal and other control factors are also included in the regressions. $\mathrm{Age}^{2}$, gender, marital status and educational attainment are included. The individual's educational attainment level is derived from identical questions across countries in line with the International Standard Classification of Education (ISCED) provided by UNESCO (1997). Genetic and inherited traits are known to affect systematically one's health but are seldom used in studies since the lack of such information in most of the surveys. The dataset used contains suitable information for the individual genetic traits by facilitating the construction of an index derived from information regarding a variety of hereditary health conditions suffered by the individual's firstdegree relatives. Detailed definitions appear in Table 1 (fifth panel).

The question on household income in the SOCIOLD survey is similar to that in the European Community Household Panel Survey, namely, "Which of the following income categories best describes your total 2003 household income from all sources (including unemployment, disability or other benefits, pensions, investments and dividends), after tax and other deductions?"3

A range of 13 income categories, comparable among countries, is offered to the respondents. The use of income ranges is preferred as it limits the non response and encourage of respondents to provide accurate information. In the present paper the continuous measure of income is derived by taking the middle value from the income categories for each participant. The income amount is equivalised based on the household members with weights similar to those used in ECHP survey. The average household income appeared to closely trace the respective income obtained from the ECHP.

Importantly, the survey provides information on the individual's SES in childhood. Respondents are asked how well-off their family was when the respondent started school. Three response options are offered (average, below average, above average). The question is phrased deliberately in simple terms as to convey the general sense of

\footnotetext{
${ }^{2}$ Age squared was also included in the regressions to test for a non-linear effect of age on health but the effect turned out to be not statistically significant.

${ }^{3}$ However, the ECHP asks for net household income per month and not per year and it includes less income categories than the present survey
} 
the SES status of the family during childhood so as to reduce the likelihood of memory bias that could plague a more detailed ranking. This information is used in order to control for family SES during childhood. Self-reported questions regarding family SES during childhood are commonly utilised in empirical research and they were found to be strong predictors of adult health (Luo and Waite, 2005).

Locus of Control (LoC) is also included as a regressor in the estimated model. Locus of control is a strong indicator of individual's personality and therefore, it is expected to affect individual choices and preferences regarding investments in health. Locus of control reveals information about individual beliefs and personality characteristics and it can be predictive of emotional behaviour (Lefcourt, 1973; Ray, 1980). The survey question on LoC is drawn from Ray (1980). He constructed a ten-item indicator. Low values in the locus of control score indicate a more "introvert" personality. Higher scores indicate individuals with relatively "extrovert" personalities. Individuals with low scores in locus of control feel that they can control their fate with their actions, in contrast to individuals with higher scores in locus of control who feel that their experiences in life are often beyond their control. Therefore, locus of control is a significant determinant of individual mental health status (Dunn, 2000) and individual preferences regarding investments in health behavior. Goldsmith et al. (1997) shows that locus of control exerts an indirect effect, through psychological capital on individual wages. Poortinga et al. (2008) argue that it is a significant determinant of individual health status and moreover, that its inclusion in the regression reduces SES inequalities in health. Bosma et al. (1999) and Lundberg et al. (2007) show that locus of control indicate that beliefs of low control over life are more common among lower socioeconomic groups and they are strongly related to mortality risk and it is strongly related to individual health status.

The sample size is 3137 observations, comprising 702 individuals for Denmark, 383 individuals for Finland, 533 individuals for France, 646 individuals for Greece, 415 for the Netherlands and 458 individuals for the UK. In view of the relatively small number of individuals per country the pooled sample is used for the analysis. In all regressions, individual country dummy variables are introduced to control for country fixed effects. Detailed definitions of the variables included in the models and their descriptive statistics are presented in Table 1. It is shown that approximately $50 \%$ of 
the sample is males. The mean age of the sample is 56 years of age. The mean value of self-assessed health status seems to be better that 'good' (65\% of the sample feels that is in "good" and "very good" health status). Similar result is implied by the other health status indicators used in the study (the mean value of the mobility index shows that half of the sample has very limited mobility problems and the mean values of the two emotional indices indicate that on average individuals enjoy a good health state with limited emotional problems).

\section{The Methodological Framework}

The literature suggests that the individual health status is a multidimensional concept. It incorporates many health facets such as physical health status, mental health status and psychological health status. Some of them may also be measured with error (e.g. self assessed health). Hence, the latent objective true heath health status of the individual is not observable by the researcher. One of the main aims of this paper is to create a continuous latent health status indicator which will incorporate the different observable dimensions of individual health but it will also take into account any possible measurement errors. In doing so, the Structural Equation Model is employed which provides an estimate of the latent health status scores with the use of Systems of Measurement Models (Jöreskog, 2000). Structural Equation Model techniques have the advantage of estimating unobserved variables to the researchers. The model accommodates the latent variables in a system of equations. The basic idea is that, after the indirect and direct pathways that operate on the relationships of interest are defined, the latent variables though can not observed by the researcher can be estimated by their relation to observed variables (multiple indicators). This methodology also takes into account the measurement errors on the observed variables. These models are known as measurement models (Maruyama, 1998).

In order to derive individual latent health scores the following Structural Equation System is estimated which relate unobserved individual Latent Health status to the observed health status indicators (SAHS, Mobility Index, Emotional Health Index1, Emotional Health Index2) for each individual $i$ as follows: 
$S A H S_{i}=a_{1 i i}$ Latent Health $_{i}+\varepsilon_{1 i}$

Mobility Index ${ }_{i}=a_{2 i}$ Latent Health $_{i}+\varepsilon_{2 i}$

Emotional Health Index $1_{i}=a_{3 i}$ Latent Health $_{i}+\varepsilon_{3 i}$

Emotional Health Index $2_{i}=a_{4 i}$ Latent Health $_{i}+\varepsilon_{4 i}$

Where $\varepsilon_{1 \mathrm{i}}, \varepsilon_{2 \mathrm{i}}, \varepsilon_{3 \mathrm{i}}, \varepsilon_{4 \mathrm{i}}$ are the error in measurement of the true objective Latent Health status as measured by the SAHS, Mobility Index, Emotional Health Indexl, Emotional Health Index2 health indices, respectively.

The above Structural Equation System (1)-(4) is estimated by using Maximum Likelihood $^{4}$ to obtain an estimate of the individual objective Latent Health status.

After obtaining the estimate of the objective Latent Health status the following model is estimated:

Latent Health $=\beta_{1 i}$ Equivalised Household Income I $_{i}+\beta_{2 i} X_{i}^{\prime}+u_{i}$

where individual Latent Health status is explained by the equivalised household income (the main regressor of interest in this study), the childhood socioeconomic status, the educational status and other individual characteristics $\left(X_{i}^{\prime}\right)^{5}$.

To deal with the issue of reverse causality the Instrumental Variables approach is utilised. Thus, the following model is estimated as the auxiliary regression:

Equivalised Household Income $_{i}=\gamma_{1 i}$ Latent Health $_{i}+\gamma_{2 i} X_{i}^{\prime}+\gamma_{3 i} Z_{i}^{\prime}+v_{i}$

In equation (6) individual latent health status appears as an independent variable in the right hand side of the equation, along with the rest exogenous regressors $\left(X_{i}^{\prime}\right)$. In order to achieve identification of the system of equations (5) - (6), the identifying

\footnotetext{
${ }^{4}$ Using the LISREL software. More information about the LISREL software is provided in www.ssicentral.com/.

${ }^{5}$ A detailed explanation of the variables included in the models and their descriptive statistics are presented in Table 1.
} 
restrictions $Z_{i}^{\prime}$ are included in equation (6). The instruments $Z_{i}^{\prime}$ should be relevant, that is they must be jointly significantly correlated with the Equivalised Household Income. They should also be valid, that is they should not be correlated with the error term $u$ in equation (5). Intuitively, the first condition implies that the instruments will contain sufficient information on observed Equivalised Household Income, which is not contained in the regressors vector $\mathrm{X}$, while the second requirement ensures that their impact on Latent Health in equation (5) comes exclusively from their correlation with observed Equivalised Household Income. Although, the above statistical properties of the identifying restrictions should be satisfied, they must also be justified by economic intuition. The three instrumental variables are:

1. whether the respondent ever bought valuable paintings or other art collections,

2. whether the respondent privately pays for his or her children education, and

3. whether the respondent or any other household member has ever won on the lottery or inherited more than 14,000 euros.

The three instruments are expected to affect the household financial situation, since they reflect specific aspects of an individual's position in the income distribution but there is no compelling reason to expect that they would affect the health state of the individual.

In order to statistically investigate the relevance of the above instruments the F-test of their joint significance in the first-stage regressions (equation 6) is employed. If the chosen excluding restrictions are "weak", i.e. have little explanatory power then the bias in the estimated IV coefficients is expected to increase (Hahn and Hausman, 2002). Stock and Yogo (2002) provide the tables of the critical values for testing the presence of weak instruments. The critical value is a function of the number of included endogenous regressors (Equivalised Household Income), the number of instrumental variables, and the desired maximal bias of the IV estimator relative to OLS (Stock and Yogo, 2002). Table 2 presents the joint significance F-tests performed for equation (6). The test rejects the weak instruments hypothesis if the Fstatistic exceeds the critical value (13.91). Therefore, the weak instruments hypothesis is rejected. 
Regarding the issue of instruments independence from the error process, the Sargan over-identification test is used. This statistic, which equals the number of observations minus the degree of freedom, times $\mathrm{R}^{2}$, follows the Chi-square distribution. A rejection of the null hypothesis (of correct model specification and orthogonality conditions) casts doubt on the validity of the instrumental variables, since they are either not truly exogenous or incorrectly excluded from the equation. The performed Sargan tests in Table 2, suggests that the instruments do not jointly exerting any statistically significant effect on Latent Health, since they are not correlated to the error process $u$.

Finally, it is important to formally establish the presence of endogeneity/ reverse causality bias. Since, the IV estimator always has a larger asymptotic variance than the OLS estimator, there is loss of efficiency in the former approach. Hence, the necessity of resorting to instrumental variables should be statistically assessed. Two alternative, asymptotically equivalent, tests, the Durbin-Wu-Hausman and the WuHausman are employed to examine whether OLS is inconsistent and IV is required (Table 3). A rejection of the null hypothesis implies that the OLS estimator does not yield consistent estimates due to endogeneity and therefore the IV estimator should be used. The test rejects the null hypothesis at $10 \%$ level of significance (Table 3), implying the endogeneity of the Equivalised Household Income variable in equation (5). This justifies the choice of the IV approach. Yet, in view of the level of significance it may be prudent to correct for endogeneity of household income, hence the corrected versions of the estimates are discussed below but the OLS estimates are also reported.

\section{Empirical Results}

\subsection{Latent Health Status and its Correlates}

Table 4 reports the results of the Structural Equation Model on the relationship between the observed individual health state variables and latent health status (eq. 14). The system is also presented in the path diagram (Graph 1) that gives a graphical description of the estimated links. 
The results are straightforward. Self-assessed health status appears to be strongly and positively related to latent health status. The mobility index is negatively and statistically significantly related to latent health. Finally, the Emotional Health Index2, where higher scores indicate the absence of emotional or psychological health problems, is related positively with higher latent health status. The Emotional Health Index 1 is not found to be associated with latent health. From the estimation of the above model the individual latent health scores are derived.

\subsection{The Determinants of Latent Health Status}

The estimation results of the auxiliary regression (6) are reported in Table 5 for completeness. However, they are not discussed for space considerations. The Table 6, first column, reports the results of OLS regressions of the individual health function ${ }^{6}$. The second column reports the results of the IV regressions, which takes into account the endogenous nature of the latent health -individual household income relationship.

In the OLS estimation the effect of equivalised household income turns out to be statistically significant and positively related to latent health. Importantly, even after the endogeneity/reverse causality correction, the relationship remains both positive and statistically significant. Household income is found to be a strong predictor of various dimensions of health status in the relevant literature (Nummela et al., 2007; Peiró, 2006). In line with Lindahl (2005), the relationship between income and health remains significant, event after endogeneity corrections.

The literature on the effects of childhood socioeconomic conditions on adult health is rather limited. Kuh \& Wadsworth (1993) argue that there are several pathways through which childhood experiences may affect health status in adulthood. Indeed, the findings of the present study indicate that individual SES during childhood has an independent and significant effect on the health of individuals in late adulthood revealing the long term repercussions of childhood poverty. Harper et al. (2002) argue that childhood socioeconomic circumstances are predictive of adult health but adult SES is a stronger predictor of adult health, implying that favourable conditions in later

\footnotetext{
${ }^{6}$ Heteroskedasticity corrected standard errors are reported through out.
} 
life can offset the negative health effects of low SES during childhood. The present study shows that respondents whose families belonged to a higher SES during their childhood, experience better health in comparison to the remainder. These findings are in line with the relevant literature. For instance, Luo and Waite (2005) utilises a similar childhood SES indicator with the present study to report results well-matched with the present findings. Lahelma et al. (2006), Rahkonen et al. (1997) and van de Mheen et al. (1998) also show that low socioeconomic position in childhood can lead to increased health problems or mortality in adulthood. In line with the literature, education level is found to have positive effects on health (Hagen et al., 2006; Von dem Knesebeck et al., 2006). Finally, a surprising result is that there appear to be no age effects on health. However, the range of ages included in the sample is narrow (45 and 65 years). Hence, after controlling for psychological and genetic loading and education one should not expect a substantial effect of ageing on health given the narrow age range of middle aged individuals included in this study.

These findings highlight the deleterious effect of childhood and current low household income and household poverty on health for individuals at their later stages of their working life even after controlling for a host of other personal characteristics including hereditary traits and psychological disposition reflected in the locus of control factor.

A robust effect of the genetic factor on health is important. Whether first-degree relatives have suffered diseases known to be of a hereditary nature is strongly associated with lower health state. Adams et al. (2003) show that hereditary health problems can affect individuals' health state and indirectly their capability to work and hence their productivity. Moreover, the locus of control index is found to be associated with health. Research indicates that people with low scores in locus of control tend to have more adaptive behaviours, take a more active interest in their health care and experience more positive psychological and physical health outcomes (Oberle, 1991) compared to the remainder. This study confirms that individuals with low scores in locus of control experience better health state in comparison to the remainder. To the knowledge of the authors there are no studies on the income-health relationship that control for the above factors. 


\section{Conclusions}

This paper investigates the SES determinants of individual health status. It introduces a methodology that enables the construction of an index for the individual latent health status that incorporates various observed dimensions of the individual health status but, importantly, it takes into account measurement errors in these observed health dimensions by using Structural Equation Modelling techniques. It also takes into account the reverse causality between household income and health. Although the study uses a cross section dataset which does not permit the study of the short term dynamics of the health-SES relationship, it provides some evaluation of the effect of childhood SES on health during the later adulthood

A strong and positive relationship between household income and health is observed after controlling for reversed causality and a host of other factors including hereditary factors and the individual's locus of control. The effect of personality traits and genetic factors on health is often ignored in previous research. Importantly, there appears to be a significant independent effect of SES position in childhood on health status at the later stages of the working life.

The above highlight the long term repercussions of poverty on health. There appear to be an intricate mechanism through which childhood poverty affects adult health. One should expect that SES status at childhood may affect not only the individuals' health status at childhood (Dooley and Vurtis, 1998), but also their physical development (Currie and Stabile, 2003), their education and their preferences at youth regarding the intertemporal discount rates for future investments in health and education (Chapman and Elstein 1995; Smith, 2008). These should be expected to affect, in turn, their investments in future health, their later health and their earnings capacity throughout the life course. The above finding has important implications for policy. If childhood and current low SES is reflected in low health status at the later stages of the working life, then SES should be expected to have a significant and independent effect on the productive capabilities and labour market participation of the older individuals over and above of the effects that are implied by the frailty attributable to advancing age. This has important implications for the labour market participation of the older population and early retirement decisions in an era of aging populations in Europe. 
This should be expected to have a direct and deleterious effect on national budgets for public health, health services and social security. Overall, it appears that policies aiming at improving population health may be largely facilitated by policies aiming at reducing the exposure of the young to poverty. 


\section{References}

Adams, P., Hurd, M.D., McFadden, D., Merrill, A., Ribeiro, T., 2003. Healthy, wealthy, and wise? Tests for direct causal paths between health and socioeconomic status. Journal of Econometrics, 112: 3-56.

Allison, A.R., Foster, J.E., 2004. Measuring health inequality using qualitative data. Journal of Health Economics, 23: 505-524.

Blakely, T.A., Lochner, K., Kawachi I., 2002. Metropolitan area income inequality and self-rated health-A multi level study. Social Science \& Medicine, 54: 65-77.

Blaxter, Mildred. 1990. Health and Lifestyles. London: Tavistock/Routledge.

Bosma, H., Schrijvers, C., Mackenbach, J.P., 1999. Socioeconomic inequalities in mortality and importance of perceived control: cohort study. British Medical Journal, 319: 1469-1470.

Buckley, N.J., Denton, F.T., Robb, A.L., Spencer, B.G, 2004. The transition from good to poor health: an econometric study of the older population. Journal of Health Economics, 23: 1013-134.

Contoyannis, P., Jones, A.M., Rice, N., 2004. The dynamics of health in the British Household Panel Survey. Journal of Applied Econometrics, 19: 473-503.

Chapman, G. B. and Elstein A. S,. 1995. Valuing the future: Temporal discounting of health and money. Medical Decision Making, 15, 4, 373-386

Crossley, T. F., Kennedy, S., 2002. The reliability of self-assessed health status. Journal of Health Economics, 21: 643-658.

Currie, J., Stabile, M., 2003. Socioeconomic Status and Child Health: Why Is the Relationship Stronger for Older Children? The American Economic Review, 93 (5): 1813-1823.

Demakakos, P., Nazroo, J., Breeze, E., Marmot, M., 2008. Socioeconomic status and health: The role of subjective social status. Social Science and Medicine, 67(2): 330340.

Dooley, M.D., Curtis, L., 1998. Child health and family socioeconomic status in the Canadian national longitudinal survey of children and youth. Mimeo, McMaster University.

Duncan, G. J., Daly, M. C., McDonough, P., Williams, D.R. (2002) Optimal Indicators of Socioeconomic Status for Health Research. American Journal of Public Health, 92(7): 1151-1157. 
Dunn, J.R., 2000. Housing and Health Inequalities: Review and Prospects for Research, Housing Studies, 15(3): 341-366.

Ecob, R., Davey Smith, G., 1999. Income and health: What is the nature of the relationship? Social Science \& Medicine, 48(5): 693-705.

Ettner, S.L., 1996. New evidence on the relationship between income and health. Journal of Health Economics, 15: 67-85.

Everson, S.A., Maty, S.C., Lynch, J.W., Kaplan, G.A., 2002. Epidemiologic evidence for the relation between socioeconomic status and depression, obesity, and diabetes. Journal of Psychosomatic Research, 53: 891-895.

Fuchs, V.R., 2004. Reflections on the socio-economic correlates of health. Journal of Health Economics, 23: 653-661.

Gardner, J., Oswald, A., 2004. How is mortality affected by money, marriage and stress? Journal of Health Economics, 23(6): 1181-1207.

Goldman, N., Korenman, S., Weinstein, R., 1995. Marital status and health among the elderly. Social Science \& Medicine, 40: 1717-1730.

Goldsmith, A.H., Veum, J.R., Darity, W.Jr., 1997. The impact of psychological and human capital on wages", Economic Inquiry, vol.XXXV: 815-829.

Groot, W., 2000. Adaptation and scale of reference bias in self-assessments of quality of life. Journal of Health Economics, 19(3): 403-420.

Grundy, E., Holt, G., 2000. Adult life experiences and health in early old age in Great Britain. Social Science \& Medicine, 51: 1061-1074.

Hagen, K.B., Tambs, T., Bjerkedal, T., 2006. What mediates the inverse association between education and occupational disability from back pain?-A prospective cohort study from the Nord-Trøndelag health study in Norway. Social Science and Medicine, 63(5): 1267-1275.

Harper, S., Lynch, J., Hsu, W. L., Everson, S.A., Hillemeier, M.M., Raghunathan, T.E., Salonen, J.T., Kaplan, G.A., 2002. Life Course Socioeconomic Conditions and Adult Psychosocial Functioning. International Journal of Epidemiology, 31: 395403.

Hahn, J. and Hausman J. 2002. Notes on Bias in Estimators for Simultaneous Equation Models. Economics Letters. 75(2): 237-241.

Hernández-Quevedo, C., Jones, A.M., Rice, N., 2008. Persistence in health limitations: a European comparative analysis. Journal of Health Economics, 27(6): $1472-1488$. 
Hurd, M., Kapteyn, A., 2003. Health, Wealth, and the Role of Institutions. Journal of Human Resources, 38(2): 386-415.

Johansen, E., A. Skalli, I Theodossiou (Eds). 2006. Are the Healthier Wealthier or the Wealthier Healthier? The European Evidence. ETLA publications, Helsinki, Finland.

Jöreskog, K.G., 2000. Latent Variable Scores and their Uses. LISREL user guide.

Kiuila, O., Mieszkowski, P., 2007. The effects of income, education and age on health. Health Economics, 16: 781-798.

Kuh, D.J.L., Wadsworth, M.E.J., 1993. Physical health status at 36 years in a British national birth cohort. Social Science and Medicine, 37: 905-16.

Lahelma, E., Laaksonen, M., Martikainen, P., Rahkonen, O., Sarlio-Lähteenkorva, S., 2006. Multiple Measures of Socioeconomic Circumstances and Common Mental Disorders. Social Science \& Medicine, 63(5): 1383-1399.

Lefcourt, H.M., 1973. The function of the illusions of control and freedom. American Psychologist, 28: 417-425.

Lindahl, M., 2005. Estimating the Effect of Income on Health and Mortality Using Lottery Prizes as an Exogenous Source of Variation in Income. Journal of Human Resources, 40(1): 144-168.

Lindeboom, M., van Doorslaer, E., 2004. Cut-point shift and index shift in selfreported health. Journal of Health Economics, 23: 1083-1099.

Lundberg, L., Bobak, M., Malyutina, S., Kristenson, M., Pikhart, H., 2007. Adverse health effects of low levels of perceived control in Swedish and Russian community samples. BMC Public Health, 7: 314-324.

Luo, Y., Waite, L.J., 2005. The Impact of Childhood and Adult SES on Physical, Mental, and Cognitive Well-Being in Later Life. Journal of Gerontology, 60B(2): S93-S101.

Lynch, J.W., Kaplan, G.A., Shema, S.J., 1997. Cumulative impact of sustained economic hardship on physical, cognitive, psychological, and social functioning. The New England Journal of Medicine, 337: 1889-1895.

Mackenbach, J.P., Bouvier-Colle, M.H., Jougla, E., 1990. Avoidable Mortality and Health Services: A Review of Aggregate Studies. Epidemology and Community Health, 44: 106-11.

Martelin, T., 1994. Mortality by indicators of socioeconomic status among the Finnish elderly. Social Science \& Medicine, 38: 1257-1278. 
Maruyama, G.M., 1998. Basics of Structural Equation Modelling. London: Sage (eds).

Mayer, K.U., Wagner, M., 1993. Socio-economic Resources and Differential Ageing. Ageing and Society, 13(4): 517-50.

Navarro, V., 1990. Race or Class Versus Race and Class: Mortality Differentials in the United States. The Lancet, 336(8725): 1238-40.

Nummela, O.P., Sulander, T., Heinonen, H.S., Uutela, 2007. Self-rated health and indicators of SES among the ageing in three types of communities. Scandinavian Journal of Public Health, 35 (1): 39-47

O' Reilly, D., 2002. Standard indicators of deprivation: do they disadvantage older people? Age and Ageing, 31: 197-202.

Oberle, K., 1991. A decade of research in Locus of Control: What have we learned? Journal of Advanced Nursing, 16: 800-806.

Peiró, A., 2006. Happiness, satisfaction and socio-economic conditions: Some international evidence. The Journal of Socio-Economics, 35(2): 348-365.

Poortinga, W., Dunstan, F.D., Fone, D.L., 2008. Health locus of control beliefs and socio-economic differences in self-rated health. Preventive Medicine, 46: 374-380.

Rahkonen, O., Lahelma, E., Huuhka, M., 1997. Past or present? Childhood living conditions and current socioeconomic status as determinants of adult health. Social Science and Medicine, 44: 327-36.

Ray, J., 1980. Belief in luck and locus of control. The Journal of Social Psychology, 111: 299-300.

Smith, J.P, 2008. The Impact of Childhood Health on Adult Labor Market Outcomes. UCD Geary Institute, Discussion Paper Series 14/2008.

Smith, J.P. 1999. Healthy Bodies and Thick Wallets: The Dual Relation Between Health and Economic Status. Journal of Economic Perspectives, 13(2): 145-66.

Smith, J.P., Kington, R.S., 1997a. Demographic and Economic Correlates of Health in Old Age. Demography, 34(1): 159-70.

Smith, J.P., Kington, R.S., 1997b. Race, Socioeconomic Status and Health in Late Life. In Racial and Ethnic Differences in the Health of Older Americans, (eds.) Linda G. Martin and Beth J. Soldo, Washington, D.C.: National Academy Press: 106-62.

Stock, J.H., Yogo, M., 2002. Testing for Weak Instruments in Linear IV Regression. NBER Technical Working Papers, 0284, National Bureau of Economic Research. 
Theodossiou, I., 1998. The effects of low-pay and unemployment on psychological well-being: A logistic regression approach. Journal of Health Economics, 17: 85104.

Van de Mheen, H., Stronks, K., Looman, C.W.N., Mackenbach, J.P., 1998. Does childhood socioeconomic status influence adult health through behavioural factors? International Journal of Epidemiology, 27(3): 431-437.

Van Doorslaer, E., Jones, A.M., 2003. Inequalities in self-reported health: validation of a new approach to measurement, Journal of Health Economics, 22: 61-87.

Van Ourti, T., 2003. Socio-economic inequality in ill-health amongst the elderly. Should one use current or permanent income? Journal of Health Economics, 22: 219-241.

Van Rossum, C.T.M., van de Mheen, H., Mackenbach, J.P., Grobbee, D.E., 2000.

Socioeconomic status and mortality in Dutch elderly people-The Rotterdam study.

European Journal of Public Health, 10: 255-261.

Von Dem Knesebeck, O., Verde, P., Dragano, N., 2006. Education and health in 22 European countries. Social Science and Medicine, 63: 1344-1351.

Wagstaff, A., Paci, P., Joshi, H., 2001. Causes of inequality in health: Who are you? Where you live? Or who your parents were? Policy Research Working Paper No 2713, Washington DC: The World Bank.

Wilkinson, R.G. 1986. Income and Mortality. In Class and Health: Research and Longitudinal Data, (eds.) Richard G. Wilkinson, London, Tavistock.

Winkelmann, L., Winkelmann, R., 1998. Why are the unemployed so unhappy? Evidence from panel data. Economica, 65(257): 1-15.

Wolfe, B., van der Gaag, J., 1981. A new health status index for children. In Health, Economics, J. van der Gaag and M. Perlman (eds.), North-Holland Publishing Company.

World Health Organisation (WHO), 2003. "The burden of musculoskeletal conditions at the start of the new millennium", WHO Technical Report Series No 919, Geneva, Switzerland. 
Table 1. Definitions of Variables and Means

\begin{tabular}{|c|c|c|}
\hline Variables & Mean & Definitions \\
\hline \multicolumn{3}{|c|}{ Health variables } \\
\hline Latent Health & 0.797 & $\begin{array}{l}\text { A index of latent objective health predicted by SEM } \\
\text { regressions of health variables on individual health status } \\
\text { described below }\end{array}$ \\
\hline$S A H S$ & 2.776 & $\begin{array}{l}\text { Self-assessed health status (1: bad/very bad, 2: fair, 3: good, } \\
\text { 4: very good) }\end{array}$ \\
\hline Mobility Index & 2.385 & $\begin{array}{l}\text { Index constructed as the sum of scores in questions regarding } \\
\text { respondent's ability to bath or dress, walking one or more } \\
\text { blocks, bend, kneel or stoop, climb stairs, lift or carry } \\
\text { groceries, do moderate or vigorous activities ( } 0 \text { : absence of } \\
\text { mobility limitations - 20: presence of all the above mentioned } \\
\text { mobility limitations) }\end{array}$ \\
\hline $\begin{array}{l}\text { Emotional } \\
\text { Health Index } 1\end{array}$ & 10.648 & $\begin{array}{l}\text { Index constructed as the sum of scores in questions regarding } \\
\text { respondent's recent emotional condition, i.e. feeling slowed } \\
\text { down, tense, having worrying thoughts, sudden feelings of } \\
\text { panic, feeling cheerful, enjoy a good book or TV programme, } \\
\text { trouble at sleeping, easily bored or irritated, difficulty in } \\
\text { concentrating, lonely }(0 \text { : absence of emotional health } \\
\text { problems }-30 \text { : presence of emotional health problems })\end{array}$ \\
\hline $\begin{array}{l}\text { Emotional } \\
\text { Health Index } 2\end{array}$ & 8.889 & $\begin{array}{l}\text { Index constructed as the sum of scores in questions regarding } \\
\text { respondent's recent emotional condition, i.e. whether the } \\
\text { respondent is feeling that enjoys the things that used to enjoy, } \\
\text { looking forward with enjoyment to things, laugh and see the } \\
\text { funny side of things, is irritable, having lost interest in his/her } \\
\text { appearance ( } 0 \text { : presence of emotional health problems }-20 \text { : } \\
\text { absence of emotional health problems) }\end{array}$ \\
\hline
\end{tabular}

Income and Socioeconomic Status (SES) variables

Equivalised

Household

Income

High SES in

Childhood

0.123

Average SES

in Childhood

0.518

Low SES in

Childhood
Total net household income (gross for the UK) from all sources

3.468 for the year 2003 adjusted for PPP (income is divided by 10,000 for all countries)

SES in childhood (1: the respondent's family was above average SES when he/she started school, 0: otherwise)

SES in childhood (1: the respondent's family was of average SES when he/she started school, 0: otherwise)

SES in childhood (1: the respondent's family was below average 0.359 SES when he/she started in school, 0: otherwise), omitted from regressions 
Table 1. Definitions of Variables (continued)

\begin{tabular}{|c|c|c|}
\hline Variables & Mean & Definitions \\
\hline \multicolumn{3}{|l|}{ Education } \\
\hline $\begin{array}{l}\text { Higher } \\
\text { Education }\end{array}$ & 0.504 & $\begin{array}{l}\text { Educational Status (1: higher educational status, 0: } \\
\text { otherwise) }\end{array}$ \\
\hline $\begin{array}{l}\text { Middle } \\
\text { Education }\end{array}$ & 0.286 & $\begin{array}{l}\text { Educational Status (1: middle educational status, 0: } \\
\text { otherwise) }\end{array}$ \\
\hline $\begin{array}{l}\text { Lower } \\
\text { Education }\end{array}$ & 0.210 & $\begin{array}{l}\text { Educational Status (1: lower educational status, 0: } \\
\text { otherwise), omitted from regressions }\end{array}$ \\
\hline \multicolumn{3}{|c|}{ Demographic variables } \\
\hline Age & 56.045 & Age in years \\
\hline Males & 0.507 & Gender (1: male, 0 : otherwise) \\
\hline Females & 0.493 & Gender (1: female, 0: otherwise), omitted from regressions \\
\hline $\begin{array}{l}\text { Married/ } \\
\text { Cohabiting }\end{array}$ & 0.759 & Marital Status (1: married/ cohabiting, 0: otherwise) \\
\hline $\begin{array}{l}\text { Divorced/ } \\
\text { Widowed }\end{array}$ & 0.181 & $\begin{array}{l}\text { Marital Status (1: separated/ divorced/ widowed, } 0 \\
\text { otherwise) }\end{array}$ \\
\hline Single & 0.06 & $\begin{array}{l}\text { Marital Status (1: single, } 0 \text { otherwise), omitted from } \\
\text { regressions }\end{array}$ \\
\hline \multicolumn{3}{|c|}{ Genetic Endowments and Locus of Control variables } \\
\hline $\begin{array}{l}\text { Genetic } \\
\text { Factors } \\
\text { Index }\end{array}$ & 3.336 & $\begin{array}{l}\text { Index calculated as the sum of scores regarding first- } \\
\text { degree relatives experience of specific health problems, } \\
\text { e.g. cardiovascular, cerebrovascular, respiratory, } \\
\text { endocrine, musculo-skeletal, gastro-intestinal, genitor- } \\
\text { urinary, malignant growth, benign growth, diabetes, high } \\
\text { blood pressure (0: absence of any health problems - 18: } \\
\text { presence of all the above mentioned health problems) }\end{array}$ \\
\hline $\begin{array}{l}\text { Locus of } \\
\text { Control } \\
\text { Index }\end{array}$ & 15.902 & $\begin{array}{l}\text { Index calculated as the sum of scores in questions } \\
\text { regarding respondent's beliefs on specific questions drawn } \\
\text { from Ray (1980), the larger score indicates a more } \\
\text { "extroverted" type of personality whereas the lower the } \\
\text { score indicates a personality type more "introverted" }\end{array}$ \\
\hline
\end{tabular}


Table 1. Definitions of Variables (continued)

\begin{tabular}{|c|c|c|}
\hline Variables & Mean & Definitions \\
\hline \multicolumn{3}{|c|}{ Country of residence } \\
\hline$D K$ & 0.224 & $\begin{array}{l}\text { Country of residence (1: he respondent lives in Denmark, } \\
0 \text { : otherwise), omitted from regressions }\end{array}$ \\
\hline$F I$ & 0.122 & $\begin{array}{l}\text { Country of residence (1: he respondent lives in France, } 0 \text { : } \\
\text { otherwise) }\end{array}$ \\
\hline$F R$ & 0.170 & $\begin{array}{l}\text { Country of residence (1: he respondent lives in Finland, 0: } \\
\text { otherwise) }\end{array}$ \\
\hline$G R$ & 0.206 & $\begin{array}{l}\text { Country of residence (1: he respondent lives in Greece, } 0 \text { : } \\
\text { otherwise) }\end{array}$ \\
\hline$N L$ & 0.146 & $\begin{array}{l}\text { Country of residence (1: he respondent lives in the } \\
\text { Netherlands, } 0 \text { : otherwise) }\end{array}$ \\
\hline$U K$ & 0.132 & $\begin{array}{l}\text { Country of residence (1: he respondent lives in Great } \\
\text { Britain, 0: otherwise) }\end{array}$ \\
\hline \multicolumn{3}{|l|}{ Instruments } \\
\hline $\begin{array}{l}\text { Art } \\
\text { Collection }\end{array}$ & 0.160 & $\begin{array}{l}\text { Household (1: ever bought valuable paintings or other art } \\
\text { collections, } 0 \text { : otherwise) }\end{array}$ \\
\hline $\begin{array}{l}\text { Children's } \\
\text { Education }\end{array}$ & 0.265 & $\begin{array}{l}\text { Children's education (1: if paying for children's } \\
\text { education or private school; } 0 \text { : otherwise })\end{array}$ \\
\hline $\begin{array}{l}\text { Won Lottery/ } \\
\text { Inheritance }\end{array}$ & 0.289 & $\begin{array}{l}\text { Won in Lottery/ Inheritance (1: anyone in the family } \\
\text { ever won in lottery or received inheritance worth more } \\
\text { than } 14,000 \text { euro, } 0 \text { : otherwise) }\end{array}$ \\
\hline
\end{tabular}


Table 2. Tests for the joint significance of the instruments and over identification

Weak identification test

\begin{tabular}{cc} 
First Stage & Equivalised Household Income \\
Joint Significance of Instrumental & 17.39 \\
Variables & $(0.00)$ \\
$F(3,3133)$ & Latent Health \\
\hline Second Stage & 3.256 \\
Sargan Test & $(0.196)$ \\
Chi-sq (2) & \\
\hline
\end{tabular}

$* p$-values are presented in brackets.

Table 3. Endogeneity tests

Equivalised Household Income

\begin{tabular}{cc}
\hline $\boldsymbol{W u}$ - Hausman & 6.362 \\
$F(1,3119)$ & $(0.012)$ \\
\hline Durbin - Wu - Hausman & 6.385 \\
Chi-sq $(1)$ & $(0.012)$
\end{tabular}

* $p$-values are presented in brackets. 
Table 4. Latent Health Status Regressions

\begin{tabular}{lc}
\hline Dep. variables & Latent Health \\
\hline Self assessed Health & $0.941 * *$ \\
Mobility Index & $-2.074 *$ \\
Emotional Health Index 1 & -1.209 \\
Emotional Health Index 2 & $0.584 * *$ \\
Chi- Square & 33.551 \\
DoF & 2.000 \\
RMSEA & 0.071 \\
NFI & 0.967 \\
AGFI & 0.973 \\
Observations & 3,137 \\
Significance: *, ***** indicate statistical significance at $10 \%, 5 \%$, and $1 \%$ \\
respectively.
\end{tabular}


Graph 1. Path Diagram of Latent Health Status Structural Equation Modelling, LISREL notation

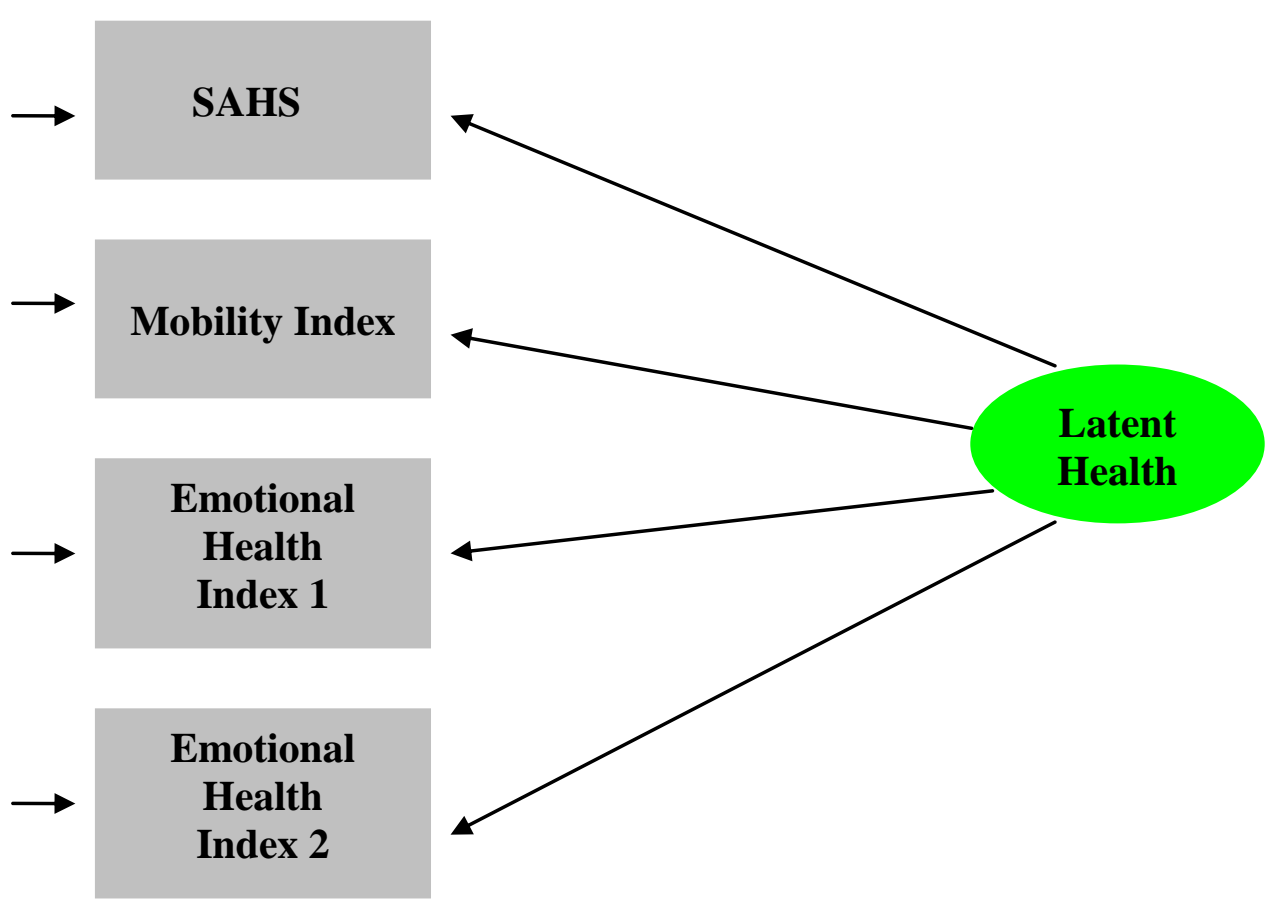


Table 5. Equivalised Household Income, First Stage Estimation, Reduced Form

\begin{tabular}{|c|c|}
\hline Ind. Variables & Equivalised Household Income \\
\hline \multicolumn{2}{|l|}{ Demographics } \\
\hline Age & $-0.045 * * *$ \\
\hline Males & $0.245 * * *$ \\
\hline Married/ Cohabiting & $1.261 * * *$ \\
\hline Divorced/Widowed & 0.247 \\
\hline \multicolumn{2}{|c|}{ Genetic Endowments and Locus of Control variables } \\
\hline Genetic Factors Index & -0.008 \\
\hline Locus of Control Index & $-0.038 * * *$ \\
\hline \multicolumn{2}{|l|}{ Education } \\
\hline Higher Education & $1.029 * * *$ \\
\hline Middle Education & $0.588 * * *$ \\
\hline \multicolumn{2}{|l|}{ Income and SES variables } \\
\hline High SES in Childhood & 0.047 \\
\hline Average SES in Childhood & 0.138 \\
\hline \multicolumn{2}{|l|}{ Country of Residence } \\
\hline$F I$ & $3.876 * * *$ \\
\hline$F R$ & $2.525 * * *$ \\
\hline$G R$ & $2.254 * * *$ \\
\hline$N L$ & $5.719 * * *$ \\
\hline$U K$ & $4.716 * * *$ \\
\hline \multicolumn{2}{|l|}{ Instruments } \\
\hline Art Collection & $1.033 * * *$ \\
\hline Children's Education & $0.427 * * *$ \\
\hline Won Lottery/Inheritance & $0.282 * * *$ \\
\hline Constant & $1.544 * * *$ \\
\hline$R$-squared & 0.454 \\
\hline$F(18,3118)$ & $\begin{array}{c}214.23 \\
(0.00)\end{array}$ \\
\hline Observations & 3,137 \\
\hline
\end{tabular}

"Significance: $* * *, * * *$ indicate statistical significance at $10 \%, 5 \%$, and $1 \%$ respectively. 
Table 6. Individual Determinants of Latent Health Stats; OLS and 2SLS

\begin{tabular}{|c|c|c|}
\hline \multirow{2}{*}{$\begin{array}{l}\text { Dependant Variable } \\
\text { Ind. Variables }\end{array}$} & \multicolumn{2}{|c|}{ Latent Health Status } \\
\hline & $O L S$ & $I V$ \\
\hline \multicolumn{3}{|l|}{ Demographics } \\
\hline Age & $-0.009 * * *$ & -0.005 \\
\hline Males & $0.091 * * *$ & $0.071 * *$ \\
\hline Married/ Cohabiting & $0.210 * * *$ & 0.098 \\
\hline Divorced/ Widowed & $0.151 * *$ & 0.124 \\
\hline \multicolumn{3}{|c|}{ Genetic Endowments and Locus of Control variables } \\
\hline Genetic Factors Index & $-0.079 * * *$ & $-0.078 * * *$ \\
\hline Locus of Control Index & $-0.024 * * *$ & $-0.020 * * *$ \\
\hline \multicolumn{3}{|l|}{ Education } \\
\hline Higher Education & $0.203 * * *$ & $0.103 *$ \\
\hline Middle Education & $0.141 * * *$ & $0.090 *$ \\
\hline \multicolumn{3}{|l|}{ Income and SES variables } \\
\hline High SES in Childhood & $0.117 * * *$ & $0.100 * *$ \\
\hline Average SES in Childhood & $0.070 * *$ & $0.066 *$ \\
\hline $\begin{array}{l}\text { Equivalised Household } \\
\text { Income }\end{array}$ & $0.029 * * *$ & $0.111 * * *$ \\
\hline \multicolumn{3}{|l|}{ Country of Residence } \\
\hline$F I$ & 0.013 & $-0.300 * *$ \\
\hline$F R$ & $0.143 * * *$ & -0.075 \\
\hline$G R$ & $-0.085 * *$ & $-0.275 * * *$ \\
\hline$N L$ & $-0.232 * * *$ & $-0.698 * * *$ \\
\hline$U K$ & $-0.179 * * *$ & $-0.556 * * *$ \\
\hline Constant & $1.440 * * *$ & $1.306 * * *$ \\
\hline$R$-squared & 0.092 & 0.038 \\
\hline$F(16,3120)$ & $\begin{array}{l}18.41 \\
(0.00)\end{array}$ & $\begin{array}{l}16.47 \\
(0.00)\end{array}$ \\
\hline Observations & 3,137 & 3,137 \\
\hline
\end{tabular}

"Significance: *,**, *** indicate statistical significance at $10 \%, 5 \%$, and $1 \%$ respectively. 